02

\title{
Лазерно-индуцированная люминесценция синтетического алмаза, легированного бором, при различной длительности лазерного импульса
}

\author{
(C) Е.А. Олейничук ${ }^{1}$, П.А. Данилов ${ }^{1}$, В.Н. Леднев ${ }^{2}$, П.А. Сдвиженский ${ }^{2}$, М.С. Кузнецов ${ }^{3}$, \\ С.А. Тарелкин ${ }^{3,4}$, М.Г. Бондаренко ${ }^{3}$ Р.А. Хмельницкий ${ }^{1}$ \\ ${ }^{1}$ Физический институт им. П.Н. Лебедева, \\ 119991 Москва, Россия \\ ${ }^{2}$ Институт общей физики им. А.М. Прохорова РАН, \\ 119991 Москва, Россия \\ ${ }^{3}$ Технологический институт сверхтвердых и новых углеродных материалов, \\ 142190 Троицк, Москва, Россия \\ ${ }^{4}$ Всероссийский научно-исследовательский институт оптико-фризических измерений, \\ 119361 Москва, Россия \\ e-mail: e.oleynichuk@lebedev.ru
}

Поступила в редакцию 20.12.2021 г.

В окончательной редакции 20.12.2021 г.

Принята к публикации 30.12.2021 г.

\begin{abstract}
Возбуждение синтетического алмаза IIb-типа ультракороткими лазерными импульсами видимого диапазона вызывает широкополосную люминесценцию УФ видимого диапазона, наблюдаемая полоса люминесценции может быть отнесена к характерной для алмазов А-полосе. Спектры фотолюминесценции сняты при разных длительностях лазерных импульсов $(0.3-6.2 \mathrm{ps})$ в зависимости от энергии в импульсе. Установлена нелинейная зависимость выхода люминесценции от интенсивности ультракоротких импульсов.
\end{abstract}

Ключевые слова: широкополосная фотолюминесценция, алмаз, легированный бором, двухфотонная люминесценция, А-полоса.

DOI: $10.21883 / \mathrm{OS} .2022 .04 .52258 .47-21$

\section{Введение}

Алмаз - уникальный материал, чьи исключительные свойства позволяют находить все более широкое применение в науке и технике, начиная от изготовления долговечных обрабатывающих инструментов, заканчивая квантовыми технологиями [1-4]. В алмазе зарегистрировано более 100 оптически активных центров [5], некоторые привлекают особый интерес [6,7]. Некоторые из этих центров присутствуют в только что выращенных алмазах, кроме того, вне зависимости от их происхождения дополнительные центры могут быть образованы вследствие облучения или ионной имплантации [8].

Фотолюминесценция - наиболее чувствительная методика выявления оптически активных центров в кристаллическом алмазе. По этой причине фотолюминесценция становится ключевым процессом, позволяющим реализовать на этой платформе новые функциональные возможности.

Алмазы типа IIb, легированные бором (BDD), особенно интересны для оптоэлектронных приложений. Сам по себе BDD-алмаз представляет собой полупроводник $p$-типа. Благодаря ряду свойств, таких как большая ширина запрещенной зоны, высокая подвижность носителей, высокая теплопроводность, а также способность противостоять экстремальным условиям, он использует- ся для исследований околоземного и дальнего космоса, в атомных станциях, электрохимии [9-11].

Также стоит отметить работу [12], в которой исследовалась широкополосная люминесценция природного алмаза, возбуждаемая ультракороткими лазерными импульсами видимого диапазона. Наблюдаемая люминесценция связывалась с наличием точечных дефектов азотных и свободных вакансий, в том числе генерируемых под действием фемтосекундного лазерного излучения в объеме алмаза. В настоящей работе исследовалось фотовозбуждение широкополосной люминесценции в синтетическом безазотном алмазе типа IIb, легированным бором, на длине волны $515 \mathrm{~nm}$ в зависимости от интенсивности лазерного излучения при фемтосекундной и пикосекундной длительностях импульса.

\section{Экспериментальная часть}

В качестве образца в настоящей работе использовался голубой синтетический (НРНT) алмаз IIb-типа, легированный бором. Образец представлял из себя тонкую пластинку толщиной $\sim 300 \mu \mathrm{m}$, размером $\sim 4 \times 4 \mathrm{~mm}$. Пластина с кристаллографической ориентацией (001) содержит в основном ростовые секторы $\{100\},\{111\}$. По центру находилась область $\sim 1 \times 1 \mathrm{~mm}$ ростово- 


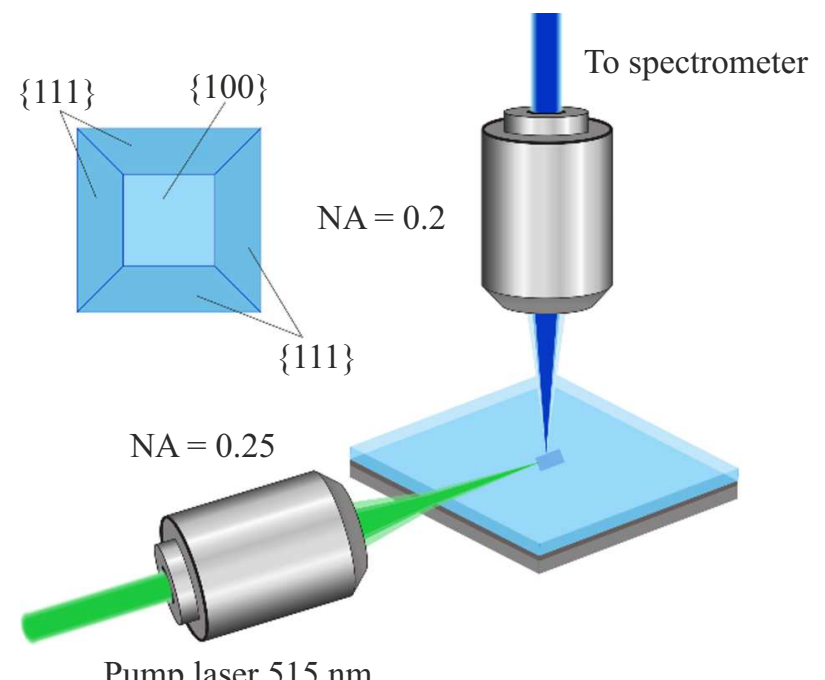

Pump laser $515 \mathrm{~nm}$

Рис. 1. Схема эксперимента. Голубой прямоугольник область фотовозбуждения, излучение с которой собирается в спектрометр. На вставке показано схематическое расположение основных секторов роста (вид сверху).

го сектора $\{100\}$, по краям - область сектора роста $\{111\}$ (рис. 1$)$.

Алмаз был предварительно охарактеризован в режиме пропускания с помощью ИК фурье-спектрометра Bruker Vertex 70v в диапазоне 2-25 $\mu \mathrm{m}$. В спектре пропускания (рис. 2) наблюдаются полосы поглощения на $2440-4070 \mathrm{~nm}\left(4095 \mathrm{~cm}^{-1}-2457 \mathrm{~cm}^{-1}\right)$, провалы в этой области являются характерными для алмаза IIb-типа и вызваны присутствием примеси бора. Концентрация бора оценивалась по полосе поглощения на $2800 \mathrm{~cm}^{-1}$ $(3570 \mathrm{~nm})$ и составила $\sim 10^{17} \mathrm{~cm}^{-3}$ и $\sim 3 \cdot 10^{17} \mathrm{~cm}^{-3}$ в секторах $\{100\}$ и $\{111\}$ соответственно. Центральная область пластины содержала меньшее количество дефектов, поэтому в ходе дальнейшей работы фотолюминесценция возбуждалась в секторе $\{100\}$.

Далее проводились измерения люминесценции и спектров комбинационного рассеяния с помощью сканирующего лазерного конфокального рамановского микроскопа Confotec MR350 с длиной волны накачки $532 \mathrm{~nm}$. На рис. 3 хорошо видна линия комбинационного рассеяния алмаза с пиком на длине волны $572 \mathrm{~nm}$, оптический фонон в данном случае составляет $1331 \mathrm{~cm}^{-1}$, энергия $-0.16 \mathrm{eV}$. Также на рис. 3 виден второй порядок комбинационного рассеяния и слабая люминесценция в красной области.

Далее для возбуждения люминесценции использовалось излучение второй гармоники $\left(\lambda_{\text {las }}=515 \mathrm{~nm}\right)$ волоконного иттербиевого лазера Satsuma (Amplitude Systemes) с варьируемой длительностью импульса и максимальной энергией в импульсе $E_{\max }=3.3 \mu \mathrm{J}$ в $\mathrm{TEM}_{00}$. Излучение лазера фокусировалось в центр пластины алмаза ( $150 \mu \mathrm{m}$ под поверхностью) микробъективом с числовой апертурой NA $=0.25$ (рис. 1). Результи-

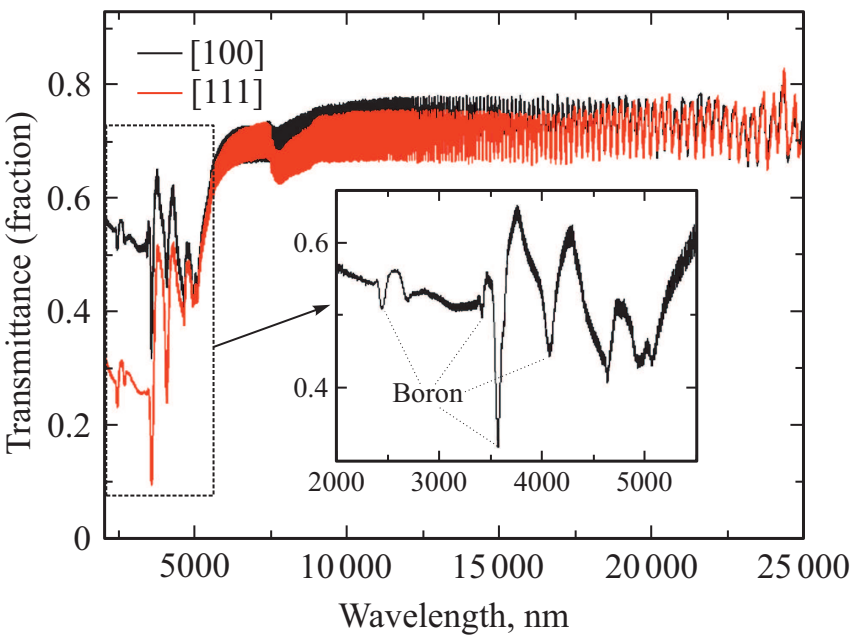

Рис. 2. Спектры пропускания борированного алмаза в диапазоне $2-25 \mu \mathrm{m}$ для соответствующих секторов роста (указаны на рисунке), показаны провалы поглощения, характерные для бopa.

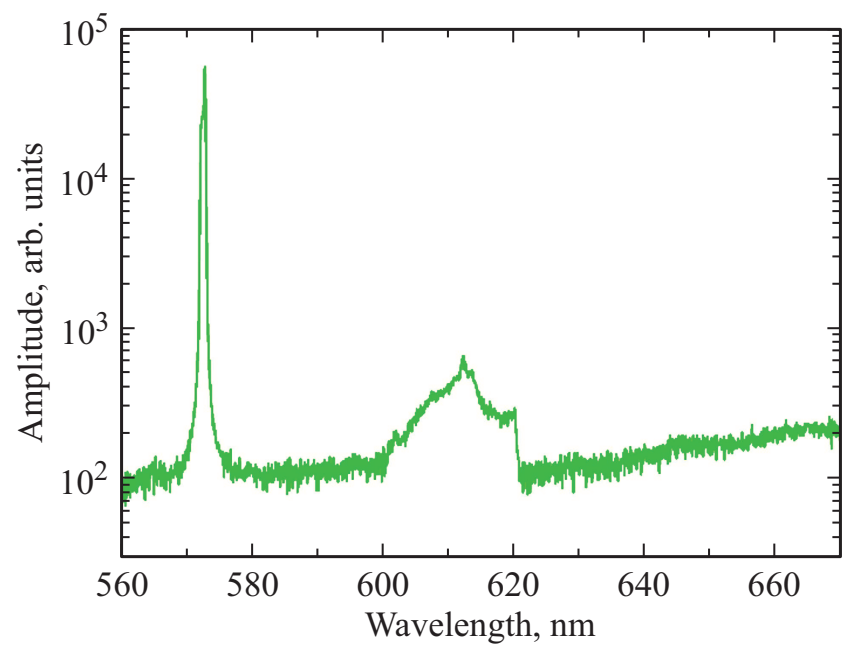

Рис. 3. Спектр люминесценции для сектора $\{100\}$ при длине волны накачки $532 \mathrm{~nm}$.

рующая фотолюминесценция фокусировалась на щель ICCD-спектрометра Andor Shamrock 303i с помощью УФ объектива ЛОМО с NA $=0.2$ в направлении, ортогональном распространению лазерного излучения накачки. Образец размещался на моторизованной трехосевой платформе Standa с минимальным шагом перемещения $150 \mathrm{~nm}$.

Измерение сигнала фотолюминесценции производилось в широком диапазоне длин волн $(300-800 \mathrm{~nm})$ импульсами длительностью 0.3, 1.3, 6.2 ps при варьируемой энергий 2-400 nJ и частоте следования импульсов $100 \mathrm{kHz}$. Во избежание повреждения детектора интенсивной накачкой область 460-530 nm не регистрировалась. 


\section{Экспериментальные результаты и их обсуждение}

Спектры на рис. 4 демонстрируют широкую полосу люминесценции для всех длительностей, выше и ниже длины волны накачки в диапазоне длин волн $350-650 \mathrm{~nm}$. Полоса с максимумом $555 \mathrm{~nm}$ соответствует однофотонному комбинационному рассеянию света на колебаниях sp3 решетки алмаза. На рис. $4, b, c$, соответствующим длительностям 1.3 и $6.2 \mathrm{ps}$, на красном плече полосы люминесценции различим пик $\sim 537 \mathrm{~nm}$. На синем плече полосы люминесценции для всех длительностей хорошо различим пик на $\sim 432 \mathrm{~nm}$, рядом с ним располагается узкий пик на $\sim 434 \mathrm{~nm}$. Для более точной интерпретации этих пиков необходимо зарегистрировать полный спектр люминесценции с центральной областью $460-530 \mathrm{~nm}$, что в нашей работе не представлялось возможным.

Широкую полосу фотолюминесценции в диапазоне $350-650 \mathrm{~nm}$ можно определить как А-полосу [5,13-15]. Спектры на рис. 4 демонстрируют смещение максимума люминесценции в более длинноволновую область спектра по мере роста длительности лазерного излучения при схожих энергиях в импульсе. Похожий эффект наблюдался в работе [16], но для алмазных CVD-пленок и был связан с наличием бора в них. В алмазах типа II А-полоса может быть связана с излучательной рекомбинацией на дислокациях [17].

Максимум амплитуды фотолюминесценции для пика на $537 \mathrm{~nm}$ в зависимости от интенсивности лазерного излучения (рис. $5, a$ ) для всех трех длительностей имеет коэффициент наклона, близкий к 1 , что говорит о линейной зависимости выхода люминесценции. В то же время для пика на $434 \mathrm{~nm}$ зависимость выхода фотолюминесценции от интенсивности падающего излучения, изображенная в двойном логарифмическом масштабе (рис. 5), носит нелинейный характер с коэффициентами наклона чуть больше единицы. Такое различие, вероятно, связано с эффективностью одно-двухфотонного возбуждения люминесценции в зависимости от интенсивности падающего излучения. Стоит отметить, что данные пики $(\sim 434$ и $537 \mathrm{~nm})$ нехарактерны для фотолюминесценции в искусственных (НРНТ) алмазах IIb-типа [5], природа их возникновения требует дополнительных исследований.

\section{Заключение}

Лазерное возбуждение синтетического алмаза, легированного бором $\left(\sim 10^{17} \mathrm{~cm}^{-3}\right)$, в видимом диапазоне вызывает люминесценцию А-полосы в диапазоне $350-650 \mathrm{~nm}$, которая демонстрирует сдвиг пика люминесценции в низкоэнергетическую область с уменьшением интенсивности накачки. Выход люминесценции лазерного излучения для всех трех длительностей
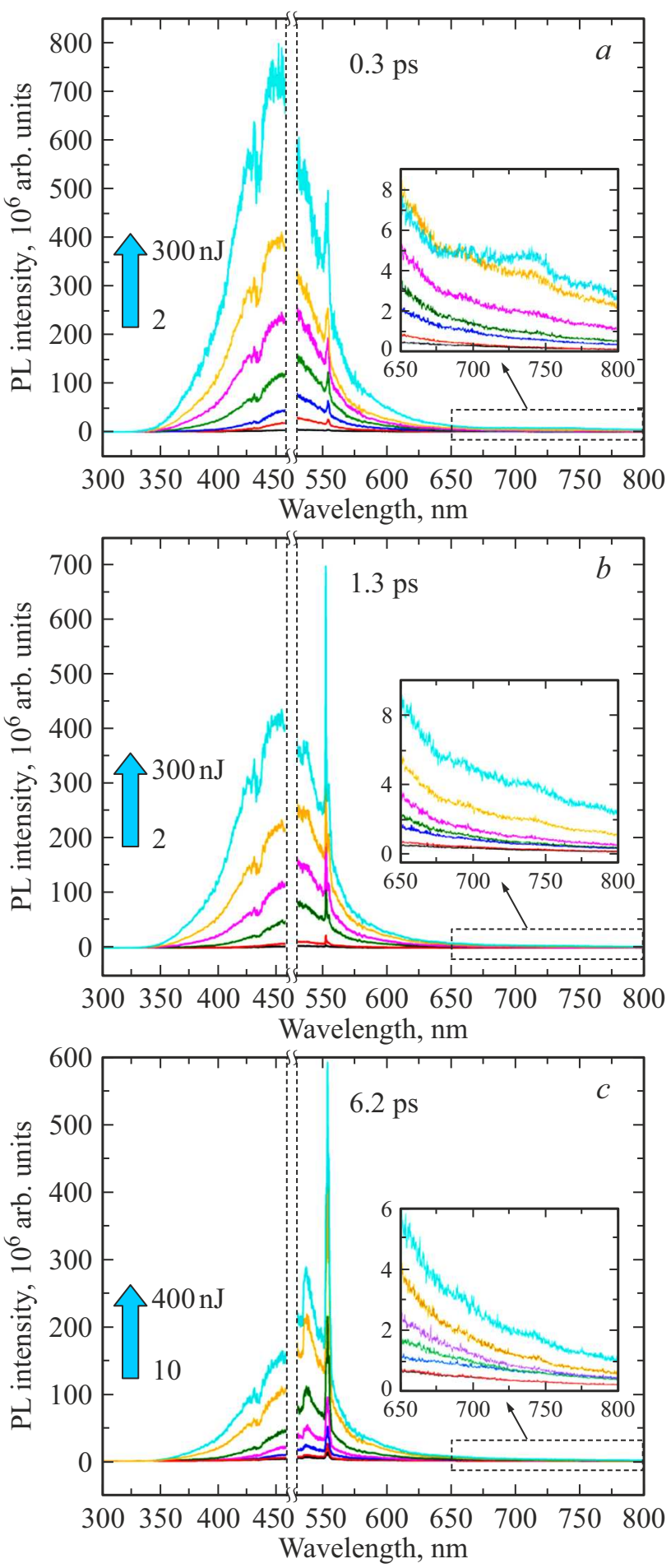

Рис. 4. Общий вид спектров фотолюминесценции борированого алмаза, возбужденного на длине волны $515 \mathrm{~nm}$ при длительностях импульса $0.3(a), 1.3(b), 6.2 \mathrm{ps}(c)$ и частоте следования импульсов $100 \mathrm{kHz}$. На вставке показана увеличенная область красной люминесценции. Спектры сшиты с учетом экспозиции при регистрации.

имеет схожие зависимости от интенсивности. Однако зависимости амплитуды пиков люминесценции ниже и 

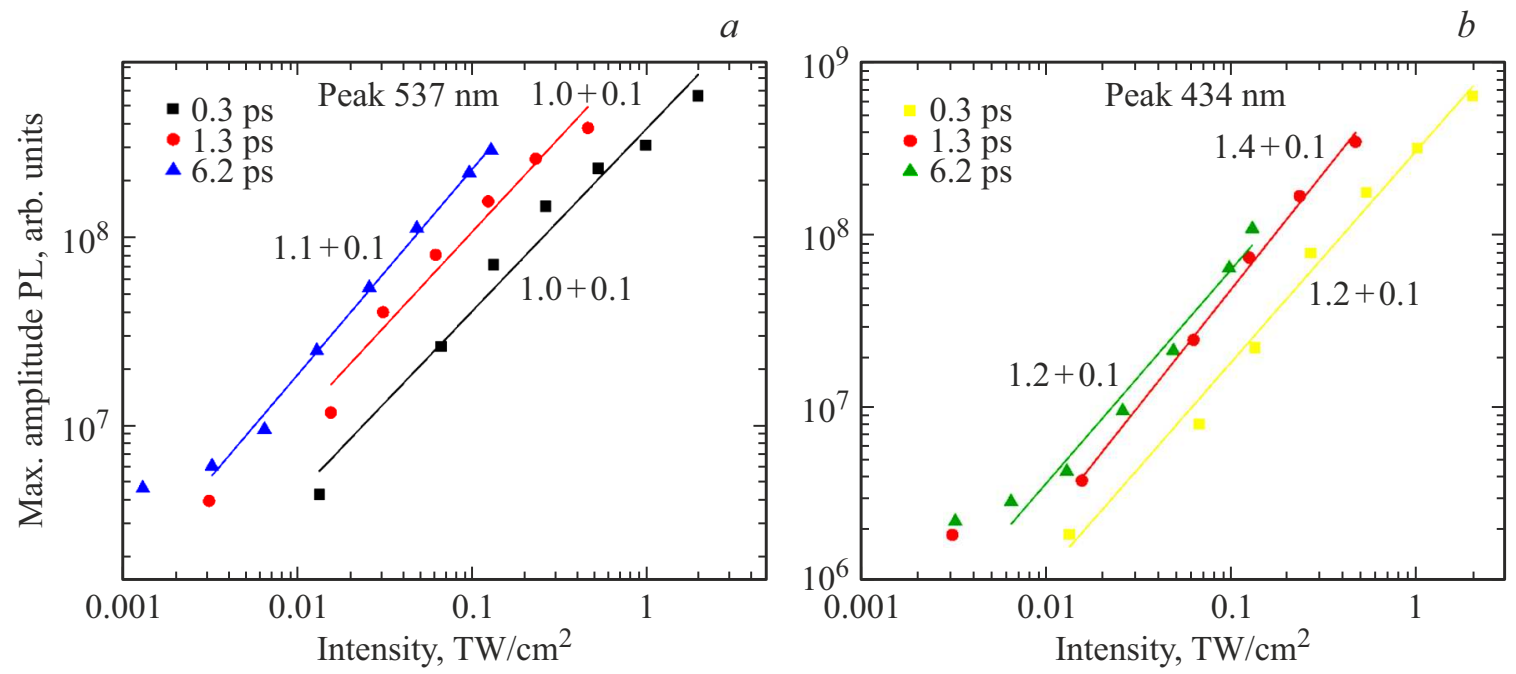

Рис. 5. Зависимость максимума амплитуды ФЛ для пиков на 537 (a) и $434 \mathrm{~nm}(b)$ от интенсивности накачки.

выше длины накачки ( 432 и $537 \mathrm{~nm})$ от интенсивности излучения лазера говорят о разных механизмах люминесценции, связанных с особенностями одно- и двухфотонного возбуждения.

\section{Финансирование работы}

Исследование выполнено за счет гранта Российского научного фонда (проект № 21-79-30063).

\section{Благодарности}

При выполнении работы использовалось оборудование ЦКП „Исследования наноструктурных, углеродных и сверхтвердых материалов“ ГНЦ ФГБНУ ТИСНУМ и ЦКП „Центр высокоточных измерительных технологий в области фотоники“ ФГУП „ВНИИОФИ““.

\section{Конфликт интересов}

Авторы заявляют, что у них нет конфликта интересов.

\section{Список литературы}

[1] S. Dhomkar, J. Henshaw, H. Jayakumar, C.A. Meriles. Sci. Adv., 2 (10), e1600911 (2016). DOI: 10.1126/sciadv.1600911

[2] C. Boehme, D.R. Mc Camey. Science, 336 (6086), 1239-1240 (2012). DOI: 10.1126/science.1223439

[3] R. Hanson, D.D. Awschalom. Nature, 453 (7198), 1043-1049 (2008). DOI:10.1038/nature07129

[4] Y.C. Chen, B. Griffiths, L. Weng, S.S. Nicley, S.N. Ishmael, Y. Lekhai, S. Johnson, C.J. Stephen, B.L. Green, G.W. Morley, M.E. Newton, M.J. Booth, P.S. Salter, J.M. Smith. Optica, 6 (5), 662-667 (2019). DOI: 10.1364/OPTICA.6.000662

[5] A.M. Zaitsev, Optical Properties of Diamond: A Data Handbook (Springer Science \& Business Media, 2013).

[6] L. Childress, R. Hanson. MRS bulletin, 38 (2), 134-138 (2013). DOI: $10.1557 / \mathrm{mrs} .2013 .20$
[7] M. Kempkes, T. Zier, K. Singer, M.E. Garcia. Carbon, 174, 524-530 (2021). DOI: 10.1016/j.carbon.2020.12.062

[8] A.T. Collins. Diamond and Related Materials, 1(5-6), 457-469 (1992). DOI: 10.1016/0925-9635(92)90146-F

[9] S.A. Tarelkin, V.S. Bormashov, S.G. Pavlov, D.L. Kamenskyi, M.S. Kuznetsov, S.A. Terentiev, D.D. Prikhodko, A.S. Galkin, H.-W. Hübers, V.D. Blank. Diamond and Related Materials, 75, 52-57 (2017). DOI: 10.1016/j.diamond.2017.01.004

[10] S.G. Pavlov, S.A. Tarelkin, V.S. Bormashov, N. Stavrias, K. Saeedi, A.F.G. van der Meer, N.A. Bekin, R.Kh. Zhukavin, V.N. Shastin, M.S. Kuznetsov, S.A. Terentiev, S.A. Nosukhin, D.D. Prikhodko, V.D. Blank, M. Wienold, H.-W. Hübers. Diamond and Related Materials, 92, 259-265 (2019). DOI: 10.1016/j.diamond.2019.01.013

[11] D. Prikhodko, S. Tarelkin, V. Bormashov, A. Golovanov, M. Kuznetsov, D. Teteruk, N. Kornilov, A. Volkov, A. Buga. J. of Superhard Materials, 41, 24-31 (2019). DOI: $10.3103 / \mathrm{S} 1063457619010039$

[12] S.I. Kudryashov, R.A. Khmelnitskii, P.A. Danilov, N.A. Smirnov, A.O. Levchenko, O.E. Kovalchuk, M.V. Uspenskaya, E.A. Oleynichuk, M.S. Kovalev. Opt. Lett., 46 (6), 1438-1441 (2021). DOI: 10.1364/OL.414583

[13] N. Yamamoto, J.C.H. Spence, D. Fathy. Phil. Mag. B, 49 (6), 609-629 (1984). DOI: 10.1080/13642818408227648

[14] H. Kawarada, Y. Yokota, Y. Mori, K. Nishimura, A. Hiraki. J. Appl. Phys., 67 (2), 983-989 (1990). DOI: $10.1063 / 1.345708$

[15] Y. Yokota, H. Kotsuka, T. Sogi, J.S. Ma, A. Hiraki, H. Kawarada, K. Matsuda, M. Hatada. Diamond and Related Materials, 1 (5-6), 470-477 (1992). DOI: $10.1016 / 0925-9635(92) 90147-G$

[16] J. Ruan, K. Kobashi, W.J. Choyke. Appl. Phys. Lett., 60 (25), 3138-3140 (1992). DOI: 10.1063/1.106748

[17] S. Kudryashov, N. Stsepuro, P. Danilov, N. Smirnov, A. Levchenko, M. Kovalev. Optical Materials Express, 11 (7), 2234-2241 (2021). DOI: 10.1364/OME.428640 